Research Article

\title{
The Socioeconomic and Spatial Dimensions of Adolescent Overweight and Obesity: The Case of Arab and Jewish Towns in Israel
}

\author{
Moran, $\mathbf{M}^{1 *}$, Goldblatt, $\mathbf{R}^{2}$, Plaut, $\mathbf{P}^{3}$, Endevelt, $\mathbf{R}^{1,4}$, Baron-Epel, $\mathbf{O}^{1}$ \\ ${ }^{1}$ School of Public Health, Faculty of Social Welfare and Health Studies, University of Haifa, Israel \\ ${ }^{2}$ School of Global Policy and Strategy, University of California, San Diego \\ ${ }^{3}$ Faculty of Architecture and Town Planning, Technion- Israel Institute of Technology \\ ${ }^{4}$ Health promotion, Community health Maccabi Healthcare Services, Tel Aviv, Israel
}

"Corresponding authors: Mika Moran, School of Public Health, Faculty of Social Welfare and Health Studies, University of Haifa, Aba Khoushi Ave 199, Mount Carmel, Haifa, Israel, Zip code: 3498838 Tel: 972-4-8288658;

E-mail: moran.mika@gmail.com

\begin{abstract}
Childhood and adolescent overweight/obesity is a major burden on public health worldwide. A growing body of empirical evidence highlights the impact of community characteristics of childhood obesity. This study explored socioeconomic and spatial variations of adolescent overweight/obesity in Israel by using an ecological approach. Towns' socioeconomic and spatial characteristics were found associated with adolescent overweight/obesity in opposite directions in Jewish and Arab towns. Adolescent overweight/obesity was found to be more prevalent in Jewish towns characterized by lower socioeconomic rank (SER) and higher peripherality levels and in Arab towns characterized by higher SER and lower peripheraliy levels. Additionally, inequalities were found to be positively related to adolescent overweight/obesity in Jewish towns. After adjusting for SER, the associations between peripherality and adolescent overweight/obesity were attuned in Jewish towns, but not in Arab towns. These findings correspond with the literature, as the results obtained for the Jewish and Arab towns are consistent with studies conducted in developed and in developing countries, respectively. Therefore, the findings highlight the importance of macro level factors enhancing obesity, and suggest that national policy may benefit from town-level interventions addressing adolescent overweight/ obesity. Several explanations to the study's findings are discussed, involving social, environmental and individual factors.
\end{abstract}

Keywords: Adolescent overweight/obesity; Peripherality; Socioeconomic rank; Wealth inequalities

\section{Introduction}

The high and rising prevalence of childhood overweight and obesity has been a major public health concern in recent years, both in the developed and in the developing world, primarily due to its' health risks and their consequences during childhood and throughout the life-course. Obesity in childhood is associated with various health complications, including orthopedic, neurological, pulmonary, and endocrine conditions ${ }^{[1]}$. Overweight and obese children are more likely to become overweight/obese adults, and thus are at higher risk for adult health problems, such as cardiovascular diseases, stroke and all-cause mortality ${ }^{[1,2]}$.

Worldwide, ten percent of school-aged children and adolescents are estimated to be overweight and obese ${ }^{[3]}$. The prevalence of childhood and adolescent overweight/obesity varies by country. Until recently, high rates of childhood overweight/ obesity were observed mainly in developed countries, with an average prevalence of above $20 \%$ in the Americas and Europe, compared to less than $10 \%$ in Africa and
Received Date: April 04, 2015

Accepted Date: June 29, 2015

Published Date: July 03, 2015

Citation: Moran, M., et al. The Socioeconomic and Spatial Dimensions of Adolescent Overweight and Obesity: The Case of Arab and Jewish Towns in Israel. (2015) J Environ Health Sci 1(2): 1-12.

\section{DOI: $10.15436 / 2378-6841.15 .012$}

Asia $^{[4]}$. However, recent studies illustrate an increase in prevalence of childhood overweight and obesity in developing regions, such as Africa and Asia ${ }^{[5,6]}$, while in developed regions childhood overweight/ obesity begins to reach a plateau (mostly in the US, Europe and Oceania $)^{[7,8]}$.

In recent years, a growing body of literature has been emphasizing the impact of community and environmental factors on childhood obesity ${ }^{[9,10]}$, beyond the effect of individual characteristics. Socioeconomic status (SES) indicators at various levels of society, from family affluence to community or national SES, may have an effect on overweight/obesity via individual factors (e.g., calorie intake, physical activity, gender and genetics) and/or via community factors (e.g., availability of healthy foods and recreation areas). Several studies have indicated that the associations between SES and childhood overweight and obesity vary between countries with different wealth characteristics $^{[11,12]}$. These studies suggest that in countries with higher income,

Copy rights: (C2015 Moran, M. This is an Open access article distributed under the terms of Creative Commons Attribution 4.0 International License. 
childhood overweight and obesity are associated with lower SES ${ }^{[8,12,13]}$, while in poorer countries childhood overweight and obesity is associated with higher SES levels ${ }^{[5,12,14]}$.

In order to further understand the socioeconomic factors affecting overweight and obesity, studies looked at inequalities within countries. These studies suggest that in communities with high wealth, disparities tend to experience worse health outcomes $^{[15]}$, including prevalence of obesity ${ }^{[16]}$. However, the associations between social inequality and health conditions vary between countries with different income levels, indicating a positive association between economic inequality with adolescent overweight/obesity in high-income countries, versus a negative association in middle-income countries ${ }^{[17]}$.

Spatial variations in childhood overweight/obesity within countries has also been studied, with a focus on urban-rural comparisons ${ }^{[18,19]}$. Similarly to the trends observed in the association between SES and overweight/obesity, these studies present an urban-rural gradient that differs by country's wealth. In economically developed regions childhood overweight/obesity rates were found to be higher in rural settings ${ }^{[19-21]}$, while in developing countries these rates were higher in urban settings ${ }^{[12,14,18,20]}$.

In this study we explore socioeconomic and spatial variations in overweight/obesity among adolescents residing in Jewish and Arab towns in Israel. Obesity in Israel has increased in the last few decades, both among adolescents ${ }^{[23]}$ and adults ${ }^{[24]}$. While it rose more steeply over time among adolescent boys in low SES towns ${ }^{[23]}$, it was found to be negatively associated with SES among women ${ }^{[25]}$. The social and economic gap between Arab and Jewish citizens in Israel is expressed in different dimensions, such as employment rate, wage, accessibility to services, and poverty ${ }^{[26]}$. Thus, given its vast socio-cultural diversity within a relatively small area (approximately 8000 sq miles), Israel provides an intriguing setting for this study. The current study aims to examine the associations between town-level prevalence of adolescent overweigh/obesity with towns' socioeconomic and spatial characteristics (town level wealth and inequalities, and intra-regional and country-scale peripherality, respectively).

\section{Methodology}

An ecological analysis approach was used to examine the associations between town's prevalence of adolescent overweight/obesity with towns' socioeconomic and spatial characteristics. This analysis included three independent data sources: (1) adolescents BMI data was obtained from the Maccabi Healthcare Services (MHS) database; (2) socioeconomic and spatial attributes of towns were obtained from the Israeli Central $\mathrm{Bu}$ reau of Statistics (ICBS) database; and (3) inequality attributes of towns were obtained from the National Insurance Institute database. The study was approved by the ethical review boards of the University of Haifa and MHS.

\section{Variables and measures}

\section{Adolescent overweight/obesity}

The dependent variable was defined as the town-level prevalence of adolescent overweight/obesity, measured by the percent of overweight and obese adolescents (that are MHS members) within each town. Adolescent overweight and obesity were defined according to the WHO growth curves, as follows: Adolescents were classified as overweight if their BMI was between the $85^{\text {th }}$ and $95^{\text {th }}$ percentile (for age and sex), and obese if their BMI was higher than the $95^{\text {th }}$ percentile (for age and sex). These cut-offs were based on the 2007 WHO's BMI-for-age growth references for boys and girls. In this study we defined adolescents as overweight/obese if their BMI was in the $85^{\text {th }}$ percentile and above.

\section{Socioeconomic variables}

Town-level wealth [Socio-economic rank (SER)]: Town-level wealth was measured by the SER, calculated by the ICBS ${ }^{[27]}$. The SER index ranges from 1-10, where 1 represents the lowest SER and 10, the highest. It integrates information regarding demography (i.e., percent of immigrants), labor force (i.e., percent of guaranteed minimal income), standard of living (i.e., average income), education (i.e., percent of high-school pupils among 17-18 years old adolescents), and social welfare (i.e., percent of receivers of national insurance welfare benefits).

Town-level Wealth inequalities (Gini coefficient): Town-level wealth inequalities were measured by the Gini coefficient, calculated by the National Insurance Institute ${ }^{[28]}$ (National Insurance Institute of Israel 2011). The Gini coefficient reflects the distribution of income among the population, and varies between 0 (perfectly equal distribution) and 1 (one individual has all the income and all others have none).

\section{Spatial variables (periperality/centrality)}

Two spatial factors were examined: (1) intra-regional and (2) country-scale pripherality/centrality. While the first indicates the towns pripherality/centrality within it's region, the latter indicates the towns pripherality/centrality on a country scale, by integrating the intra-regional measure with the distance to TelAviv area, which is considered to be Israel's economical and business center.

Intra-regional peripherality/centrality [Potential accessibility rank (PAR)]: A town's regional peripherality/centrality was measured by the PAR, as it was calculated by the $\operatorname{ICBS}^{[29]}$. The PAR indicates the proximity of a given town to all other towns in Israel, weighed by its size (and thus reflects closeness to employment opportunities, commercial and public services). The values of PAR range between 1 to 252, where towns with higher ranks are considered more likely to be central within their region (relatively large towns surrounded by other relatively large towns).

Country-scale peripherality/centrality [Peripheral rank (PER)]: The towns' level of peripherality/centrality on a country wide-scale was measured by the PER, as calculated by the ICBS $^{[29]}$. This rank integrates the aforementioned PAR with proximity to Tel-Aviv district, which is considered to be Israel's economical and business center. The values of PER range between 1 to 252, where towns with higher ranks are considered more likely to be central within their region and closer to the Tel-Aviv area. 


\section{Statistical analysis}

Statistical analyses were performed using SPSS version 16.0. Conventional descriptive statistics and t-test analysis were used to explore the towns' periperality/centrality and socioeconomic characteristics and town-level prevalence of adolescent overweight/obesity, while comparing between Jewish and Arab towns. The association between adolescent overweight/obesity and the independent variables (SER, Gini coefficient PAR and PER) were measured using Spearman coefficients. Multivariable linear regression models were calculated in order to analyze the independent association between a town's periperality/centrality and socioeconomic characteristics and adolescent overweight/ obesity prevalence. The analyses were conducted separately on two samples among Jewish and Arab towns. Arab towns include of a high majority of Arab residents, while Jewish towns include a high majority of Jewish residents. Of the 100 Jewish towns, 7 towns included mixed populations, but with a majority of Jewish population. In order to detect gender differences, some of the analyses were repeated by gender strata (boys and girls).

\section{Data extraction and sample characteristics}

An updated file including data on adolescent BMI was extracted from MHS database. MHS insures 1.9 million people in Israel, including about 300,000 adolescents aged 12-18. This database consists of approximately $25 \%$ of the Israeli population, and is likely to be representative, as MHS is obliged to insure every citizen who wishes to join it, regardless of age, sex, physical condition, or any other criterion. Around $60 \%$ of all adolescents had their BMI measured and recorded in the MHS database during the previous three years. Although this does not represent the total population in Israel, it enabled us to explore the hypothesis, as described in the objectives of the study.

The initial file included a sample BMI records of 133,041 adolescents (boys and girls aged 12-17), who reside in 1,095 towns. Towns with records of less than 100 adolescents $(n=952)$ and towns with no records of town level SER and/or Gini coefficient $(n=22)$ were excluded from this initial file. The file used in our analysis included BMI records of 114,422 adolescents $(58,021$ boys and 56,401 girls aged 12-17), who live in 121 Israeli towns (with a population of 5,600 to 815,000 residents). The town-level prevalence of adolescent overweight/ obesity includes the BMI data of a least 100 adolescents in each town.

\begin{tabular}{|c|c|c|c|c|c|c|c|c|c|}
\hline & & \multicolumn{2}{|c|}{$\begin{array}{l}\text { Overall towns sample } \\
\qquad(\mathrm{N}=121)\end{array}$} & \multicolumn{2}{|c|}{ Jewish towns $(\mathrm{N}=100)$} & \multicolumn{2}{|c|}{ Arab towns $(\mathrm{N}=21)$} & \multirow{2}{*}{$\mathrm{T}(\mathrm{df})$} & \multirow{2}{*}{$\mathrm{P}$} \\
\hline & & Mean (SD) & Range & Mean (SD) & Range & Mean (SD) & Range & & \\
\hline \multirow{2}{*}{$\begin{array}{l}\text { Socioeconomic } \\
\text { characteristics }\end{array}$} & Town level wealth (SER) & $5.43(2.19)$ & $1-10$ & $6(1.94)$ & $1-10$ & $2.71(0.35)$ & $1-4$ & $11.89(65)$ & $<0.0001$ \\
\hline & $\begin{array}{l}\text { Town level inequality } \\
\text { (Gini coefficient) }\end{array}$ & $0.41(0.05)$ & $0.31-0.60$ & $0.43(0.05)$ & $0.35-0.60$ & $0.35(0.02)$ & $0.31-0.40$ & $20.54(58)$ & $<0.0001$ \\
\hline \multirow{2}{*}{$\begin{array}{l}\text { Spatial } \\
\text { characteristics }\end{array}$} & $\begin{array}{l}\text { Country-scale peripheral- } \\
\text { ity/centrality (PER) }\end{array}$ & $155.39(70.58)$ & $1-252$ & $163.16(71.10)$ & $1-252$ & $118.38(55.92)$ & $4-216$ & $2.71(119)$ & 0.008 \\
\hline & $\begin{array}{l}\text { Intra-regional peripheral- } \\
\text { ity/centrality (PAR) }\end{array}$ & $157.77(70.57)$ & $3-252$ & $164.90(70.99)$ & $3-252$ & $123.81(58.91)$ & $7-213$ & $2.48(119)$ & 0.015 \\
\hline
\end{tabular}

Table 1 presents descriptive statistics of the socioeconomic and spatial variables of the towns. First, all socioeconomic and spatial measures are significantly higher in the Jewish towns, indicating that compared to Arab towns, Jewish towns are characterized by higher SER and greater social inequalities, as well as by higher levels of centrality at both country- and intra-regional scales. These differences reflect the gap between the Jewish and Arab population in Israel ${ }^{[26,30-31]}$. Given these differences all of the analyses in this study were conducted separately for Jewish and for Arab towns.(legend).

Preliminary correlation analysis was conducted to identify co-variability of the independent variables. The two socioeconomic measures - SER and Gini coefficient - were positively correlated in both Jewish towns $(\mathrm{r}=0.70, \mathrm{p}<0.0001)$ and Arab towns $(r=0.52 . p<0.0001)$. Similarly, and as expected by their definitions, the two spatial measures - PAR and PER - were strongly positively correlated in both Jewish and Arab towns ( $r=0.95$ and $r=0.90$, respectively. $p<0.0001$ for both). In the Jewish towns, a positive and significant correlation was observed between the socioeconomic and spatial variables. Specifically, town-level SER in the Jewish towns is positively and significantly associated with country-scale peripherality/centrality (PER) $(\mathrm{r}=0.33, \mathrm{p}=0.001)$, and with intra-regional peripherality/ centrality $(\mathrm{PAR})(\mathrm{r}=0.32, \mathrm{p}=0.001)$. At the same time, town-level inequality is positively and significantly associated with country-scale peripherality/centrality (PER) $(r=0.33, p=0.001)$, and with intra-regional peripherality/centrality $(\mathrm{PAR})(\mathrm{r}=0.35$, $\mathrm{p}<0.0001)$. On the other hand, in the Arab sector a significant positive association was observed only between town-level SER and intra-regional peripherality/centrality (PAR) $(r=0.48$, $\mathrm{p}=0.03$ ). These findings imply that in the Jewish sector, wealthier towns and towns with higher wealth disparities tend to be more central at both country- and regional scales, while in the Arab sector a town's wealth is associated with it's regional centrality, rather than with its vicinity to the economic center of the country (Tel-Aviv district). 


\section{Results}

The average prevalence of adolescent overweight/obesity was found to be significantly higher $(\mathrm{p}<0.002)$ in Arab towns than in Jewish towns (34.35\% vs $29.34 \%)$, a tendency observed both among boys $(37.04 \%$ versus $30.60 \%, \mathrm{p}<0.003)$ and girls (30.87\% versus $26.80 \%, \mathrm{P}<0.01$ ) (Table 2 ). In addition, overweight/obesity was found to be significantly higher $(p<0.005)$ in boys compared to girls in both Jewish and in Arab towns.

Table 2: The average distribution of overweight and obesity of adolescents in Israeli towns by ethnicity and gender

\begin{tabular}{|c|c|c|c|c|c|c|}
\hline & \multicolumn{3}{|c|}{$\begin{array}{c}\text { Number of adolescents per } \\
\text { town } \\
\text { mean (range) }\end{array}$} & \multicolumn{3}{|c|}{$\begin{array}{l}\text { \% overweight and obese } \\
\text { adolescents per town } \\
\text { mean (range) }\end{array}$} \\
\hline & Total & Boys & Girls & Total & Boys & Girls \\
\hline \multirow{2}{*}{$\begin{array}{l}\text { Arab } \\
\text { Towns } \\
(\mathbf{N}=21)\end{array}$} & 314 & 167 & 150 & 34.35 & 37.04 & 30.87 \\
\hline & $\begin{array}{l}(116- \\
1043)\end{array}$ & $(57-534)$ & $(59-519)$ & $\begin{array}{l}(24.4- \\
46.3)\end{array}$ & $\begin{array}{c}(22.0- \\
49.6)\end{array}$ & $\begin{array}{l}(20.9- \\
46.9)\end{array}$ \\
\hline \multirow{2}{*}{$\begin{array}{l}\text { Jewish } \\
\text { Towns } \\
(\mathbf{N}=\mathbf{1 0 0})\end{array}$} & 1080 & 578 & 538 & 29.34 & 30.6 & 26.8 \\
\hline & $\begin{array}{l}(101- \\
7507)\end{array}$ & $\begin{array}{c}(52- \\
3991)\end{array}$ & $\begin{array}{c}(47- \\
3784)\end{array}$ & $\begin{array}{c}(19.12- \\
41.34)\end{array}$ & $\begin{array}{l}(17.0- \\
42.97)\end{array}$ & $\begin{array}{c}(12.2- \\
39.6)\end{array}$ \\
\hline \multirow{2}{*}{$\begin{array}{l}\text { Total } \\
(\mathrm{N}=121)\end{array}$} & 947 & 506 & 470 & 30.21 & 31.73 & 27.47 \\
\hline & $\begin{array}{l}(101- \\
7,507\end{array}$ & $\begin{array}{c}(52- \\
3991)\end{array}$ & $\begin{array}{c}(48- \\
3784)\end{array}$ & $\begin{array}{c}(19.1- \\
46.3)\end{array}$ & $\begin{array}{c}(17.0- \\
49.6)\end{array}$ & $\begin{array}{c}(12.2- \\
46.9)\end{array}$ \\
\hline \multicolumn{4}{|c|}{$\mathrm{t}$ test (for Jewish versus Arab towns): } & $\mathrm{P}<0.002$ & $\mathrm{p}<0.003$ & $\mathrm{P}<0.01$ \\
\hline
\end{tabular}

The association between towns' prevalence of overweight/obesity and the town-level SER (table 3) showed a clear difference between Jewish and Arab towns. The correlation between these variables was negative in Jewish towns $(\mathrm{r}=-0.59$, $\mathrm{p}<0.0001)$ and positive in Arab towns $(\mathrm{r}=0.47, \mathrm{p}<0.05)$. Namely, the wealthier a Jewish town is, the lower the risk of adolescent overweight/obesity. At the same time, the wealthier an Arab town is, the higher the risk of adolescent overweight/obesity. This tendency was observed, both, among boys and girls (data not presented) though the correlation between SER and Arab girls` overweight/obesity prevalence was insignificant.

Analysis of the association between towns' prevalence of overweight/obesity and the Gini coefficient (reflecting town-level wealth inequalities) revealed a negative and significant correlation between the variables only for Jewish towns $(\mathrm{r}=-0.71, \mathrm{p}<0.0001)$, suggesting that adolescents in Jewish towns characterized by higher wealth disparities have a lower chance of being overweight/obese. Though the correlation between these variables was insignificant among Arab towns, the direction of the correlation was positive, as opposed to a negative correlation in the Jewish towns. Given the strong positive correlation between town-level SER and Gini coefficient in Jewish towns $(\mathrm{r}=0.70, \mathrm{P}<0.0001)$, the inequality-overweight/obesity correlations observed in Jewish towns may be an attributed to the SER-overweight/obesity correlations.

Analysis of the association between adolescent overweight/obesity and a town's peripherality/centrality similarly showed an opposite trend between Jewish and Arab towns (table 3). At a country-scale, central Jewish towns (i.e., higher values of PER) exhibit a lower prevalence of adolescent overweight/ obesity $(\mathrm{r}=-0.40, \mathrm{p}<0.0001)$, while central Arab towns exhibit a higher prevalence of adolescent overweight/obesity $(r=0.59$; $\mathrm{p}<0.005)$. This pattern was repeated at a regional scale, with lower rates of adolescent overweight/obesity in Jewish towns that are central within their region (i.e., higher values of PAR) $(\mathrm{r}=-0.31 ; \mathrm{p}=0.005)$, versus higher rates of adolescents overweight/obesity in Arab towns that are central within their region ( $r=0.66 ; p=0.001)$. Namely, the risk for adolescents overweight/ obesity is higher in Jewish peripheral towns (compared to Jewish central towns), and in Arab central towns (compared to Arab peripheral towns).

Given the relatively low average SER of the Arab towns, compared to Jewish towns in our sample (see Table 1), it may be assumed that the higher rates of adolescent overweight/ obesity observed in high SER and central Arab towns are attributed to the towns 'SER, rather than to their ethnic profile. To examine this assumption, we repeated the aforementioned analyses after dividing the Jewish towns sample into two sub-samples: (1) low SER Jewish towns [i.e., SER values ranging from 1-4 (which is identical to the SER range of Arab towns included in this study)] ( $\mathrm{n}=19)$, and (2) mid-high SER Jewish towns (i.e., SER values ranging from 5-6) $(\mathrm{n}=81)$. Interestingly, no significant correlation was observed among the low SER Jewish towns between adolescent overweight/obesity and the socioeconomic and spatial variables (SER and Gini coefficient; PAR and PER, respectively). On the other hand, the subsample of mid-high SER Jewish towns resulted in relatively similar correlation values to those observed when all Jewish towns $(n=100)$ was included in the analysis. These findings may suggest that the correlations observed in the Arab sector may not be attributed solely to their low SER, while in the Jewish sector they are prominent mostly in mid-high SER Jewish towns.

Table 3: Correlations between prevalence of adolescents overweight/obesity, town level SER, Gini coefficient and peripheral attributes (Spearman's rho, $\mathrm{N}=92$ )

\begin{tabular}{|c|c|c|c|c|c|}
\hline & & \multicolumn{4}{|c|}{$\begin{array}{c}\text { Percent of Adolescent overweight/ } \\
\text { obesity }\end{array}$} \\
\hline & & \multicolumn{2}{|c|}{$\begin{array}{l}\text { Jewish towns } \\
\quad(\mathrm{N}=100)\end{array}$} & \multicolumn{2}{|c|}{$\begin{array}{l}\text { Arab towns } \\
\quad(\mathrm{N}=21)\end{array}$} \\
\hline & & $\mathrm{R}$ & $\mathrm{p}$ & $\mathrm{R}$ & $\mathrm{p}$ \\
\hline \multirow{2}{*}{$\begin{array}{l}\text { Socioeconomic } \\
\text { Characteristics }\end{array}$} & $\begin{array}{l}\text { Town-level wealth } \\
\text { (SER) }\end{array}$ & $-0.59 * * *$ & 0.000 & $0.47 * *$ & 0.03 \\
\hline & $\begin{array}{l}\text { Town-level } \\
\text { inequality (GINI } \\
\text { coefficient) }\end{array}$ & $-0.71 * * *$ & 0.000 & 0.16 & 0.49 \\
\hline \multirow{2}{*}{$\begin{array}{l}\text { Spatial } \\
\text { Characteristics }\end{array}$} & $\begin{array}{l}\text { Country-scale } \\
\text { peripherality/cen- } \\
\text { trality (PER) }\end{array}$ & $-0.40 * * *$ & 0.000 & $0.59 * *$ & 0.005 \\
\hline & $\begin{array}{l}\text { Intra-regional } \\
\text { peripherality/cen- } \\
\text { trality (PAR) }\end{array}$ & $-0.32 * *$ & 0.001 & $0.66^{* *}$ & 0.001 \\
\hline
\end{tabular}

Multivariate linear regression analyses were performed in order to determine the independent effect of the socioeconomic and spatial factors on town-level adolescent overweight/ obesity (Table 4). Given the strong correlations found between the country-scale and intra-regional peripherality/centrality variables $(\mathrm{r}=0.95, \mathrm{p}<0.000$ in Jewish towns and $\mathrm{r}=0.90, \mathrm{p}<0.006$, in Arab towns), these two spatial variables were analyzed in two separate models: one that included SER and country-scale peripherality/centrality (table 4, model 1), and one that included SER and intra-regional peripherality/centrality (table 4, model 2).

The models, as presented in table 4, yielded opposite 
results for Jewish and for Arab towns, suggesting that in Jewish towns the relative weight of SER was stronger than that of the peripherality/centrality in predicting adolescent overweight/ obesity, while in Arab towns the relative weight of the peripherality/centrality was stronger than that of SER. As expected, the directions of the correlation between adolescent overweight/ obesity with SER and peripherality/centrality factors were opposite in Jewish and Arab towns (this is expressed by negative versus positive $t$ values in the Jewish and in the Arab towns, respectively). As shown in model 1 (table 4), in Jewish towns SER was a stronger predictor of adolescents overweight/obesity than PER, while in Arab towns PER remained a significant predictor, but town-level SER was no longer significantly correlated with adolescents overweight/obesity. This pattern was strengthened in the second model (table 4), showing that in Jewish towns SER remained a significant predictor, while PAR was no longer significantly correlated with adolescents overweight/obesity. An opposite result emerged in Arab towns, showing that PAR remained a significant predictor, while SER was no longer significantly correlated with adolescent overweight/obesity. These results were repeated when the models were implemented for boys and for girls, separately.

The explained variance in town-level adolescent overweight/obesity was higher for Arab towns (46-51\%) than for Jewish towns (28-31\%). In Arab towns, SER, together with PAR, explained more of the variance in adolescent overweight/ obesity than did SER together with PER (51\% vs 46\%). A different picture emerged in Jewish towns, where SER, together with PER, explained more of the variance in adolescents overweight/ obesity than did SER together with PER (31\% versus 28\%).

Table 4: Multivariable linear regression models for prevalence of overweight/obesity in Arab and Jewish towns; regression models with SER

\begin{tabular}{|c|c|c|c|c|c|c|}
\hline & & & \multicolumn{2}{|c|}{ Model 1} & \multicolumn{2}{|c|}{ Model 2} \\
\hline & & & $\begin{array}{l}\text { Jewish } \\
\text { towns }\end{array}$ & $\begin{array}{l}\text { Arab } \\
\text { towns }\end{array}$ & $\begin{array}{l}\text { Jewish } \\
\text { towns }\end{array}$ & $\begin{array}{l}\text { Arab } \\
\text { towns }\end{array}$ \\
\hline \multirow{2}{*}{$\begin{array}{l}\text { Socioeconomic } \\
\text { characteristics }\end{array}$} & \multirow{2}{*}{$\begin{array}{l}\text { Town-level } \\
\text { wealth (SER) }\end{array}$} & $\beta$ & $-0.46^{* * *}$ & 0.36 & $-0.48^{* * *}$ & 0.23 \\
\hline & & $\mathrm{t}$ & -5.34 & 2.02 & -5.46 & 1.23 \\
\hline \multirow{4}{*}{$\begin{array}{l}\text { Spatial } \\
\text { characteristics }\end{array}$} & \multirow{2}{*}{$\begin{array}{l}\text { Country-scale } \\
\text { peripherality/ } \\
\text { centrality } \\
\text { (PER) }\end{array}$} & $\beta$ & $-0.25^{* * * *}$ & $0.50^{*}$ & & \\
\hline & & $\mathrm{t}$ & -2.88 & 2.83 & & \\
\hline & \multirow{2}{*}{$\begin{array}{l}\text { Intra-regional } \\
\text { peripherality/ } \\
\text { centrality } \\
\text { (PAR rank) }\end{array}$} & $\beta$ & & & -0.17 & $0.60 * *$ \\
\hline & & $\mathrm{t}$ & & & -1.88 & 3.27 \\
\hline $\begin{array}{l}\text { Model } \\
\text { Summary }\end{array}$ & & & $\begin{aligned} & \mathrm{R}^{2}=0.31 \\
& \mathrm{P}<.001 \\
& \mathrm{~N}=100\end{aligned}$ & $\begin{array}{c}\mathrm{R}^{2}=0.46 \\
\mathrm{P}<.0001 \\
\mathrm{~N}=21\end{array}$ & $\begin{array}{c}\mathrm{R}^{2}=0.28 \\
\mathrm{P}<. .0001 \\
\mathrm{~N}=100\end{array}$ & $\begin{array}{c}\mathrm{R}^{2}=0.51 \\
\mathrm{P}<.001 \\
\mathrm{~N}=21\end{array}$ \\
\hline \multicolumn{7}{|c|}{$* \mathrm{p}<0.05, * * \mathrm{p}<0.01, * * * \mathrm{p}<0.001$} \\
\hline
\end{tabular}

Additional multivariate models were conducted among Jewish towns to predict adolescent overweight/obesity by the Gini-coefficient and peripherality/centrality (both PER and PAR) (data not presented). As expected based on the strong positive correlation between the Gini-coefficient and SER in Jewish towns, these models yielded similar results to those of the models presented in table 4, indicating that the associations between peripherality/centrality (both PER and PAR) and adolescent overweight/obesity were attuned or insignificant after adjustment for the Gini-coeffiecient.

\section{Discussion}

This study examined the associations between prevalence of adolescent overweight/obesity and socioeconomic and spatial characteristics in Jewish and Arab towns in Israel. A recurring pattern in our findings suggests that both, among Jewish and Arab towns, the prevalence of adolescent overweight/obesity was associated with the socioeconomic and spatial characteristics of the town of residence, but in an opposite direction. Adolescent overweight/obesity was found to be more prevalent in Jewish towns characterized by lower SER and higher peripherality levels and in Arab towns characterized by higher SER and lower peripheraliy levels.

Overall, these findings correspond with the literature, as the results obtained for the Jewish towns are consistent with studies conducted in developed countries ${ }^{[9,19]}$, while our findings among Arab towns support previous studies conducted in developing countries ${ }^{[5,18]}$. In other words, when it comes to socioeconomic and spatial determinants of overweight/obesity, Jewish towns seem to behave like developed countries/modern societies, while Arab towns behave like developing countries/ traditional societies. To some extent, these similarities may have been anticipated, given the socioeconomic gap between Jewish and Arab communities in Israel in general ${ }^{[26,30,31]}$ and, specifically in our sample (see table 1). Therefore, our findings confirm existing literature, on a smaller geographical scale (i.e. the town level), and thereby strengthens the importance community level factors that may impact obesity.

While this study focused on town-level factors, overweight/obesity is known to be related to many factors at various level ranging from biological and individual factors to community and environmental factors ${ }^{[9,32,33]}$. Therefore, the discussion below seeks to explain the associations observed in this study by several mechanisms, involving social, environmental and individual factors that are known to be related with obesity.

Adolescent overweight/obesity was found to be related to SER in Jewish and Arab towns in opposite directions (negative and positive correlations, respectively). The findings correspond with previous studies conducted in the USA ${ }^{[34,35]}$, indicating negative and positive associations between SER and adolescent overweight/obesity in white and minority populations, respectively.

The negative correlation between SER and overweight/ obesity, as observed in the Jewish sector, stands in line with extensive literature, mainly from developed countries/modern societies $^{[8,34,35]}$. Although the SER measure used here indicates the socioeconomic level of a given town, it also reflects, at least to some extent, socioeconomic factors at other levels, ranging from individual to social and environmental levels. At the individual level, poorer towns may have a greater proportion of poor residents, who may be more prone to overweight/obesity due to various reasons, such as less leisure time for physical activity $^{[36,37]}$ and/or low awareness of healthy nutrition ${ }^{[38]}$. At the environmental level, municipalities of lower ranked towns may have less funding for building healthier environments (including high access to healthy food and recreational spaces). It was also suggested that stress from living at the bottom of the hierarchy of society may explain this association in the developed world, however only when high calorie food is available ${ }^{[16]}$. Future research may benefit from employing multi-level approaches to 
explore the potential impact of SER indicators at various levels (individual, social, environmental) on overweight/obesity.

In the Arab sector, adolescent overweight/obesity was found to be positively related to a town's SER level. The assumption that these association are attributed to the low-SER of Arab towns, rather than to it's ethnic profile, was rejected as these associations were not repeated in low-SER Jewish towns. These findings suggest that the correlations observed in the Arab sector may not be attributed solely to their low SER, while in the Jewish sector they are prominent mostly in mid-high SER Jewish towns. The opposing associations between wealth and obesity among the Arab and Jewish sectors brings up theoretical challenges ${ }^{[39]}$. Given the overall low-SER of Arab towns, these findings can be explained by the fact that in poor communities where funds limit caloric intake, the more financial resources available, the more food and prepared industrial food they can obtain, and therefore the individual will have a higher chance of being overweight or obese ${ }^{[32]}$. It should be remembered that obesity has been called a disease of affluence, also because of this reason ${ }^{[40]}$.

In this study wealth inequality was found to be negatively associated with adolescent overweight/obesity in Jewish towns, but not in the Arab towns. Similar findings were reported in a study conducted in Los Angeles County, suggesting that neighborhoods with higher income inequalities had lower levels of obesity ${ }^{[4]}$. The positive correlation between inequality and overweight/obesity observed in Jewish towns can be explained by various mechanisms at both town- and individual levels. Given that in our study Jewish towns with higher inequalities tend to be more affluent (see table 1), it may be hypothesizes that this, at least partially, contributes to the inequality-overweight/obesity positive association. In other words, it may be assumed that, given their higher SER, in towns with higher inequality more funding among local authorities are allocated for developing policies towards the creation of non-obesogenic environments (i.e., walkable streets with paved and illuminated sidewalks, sports facilities, community walking events, more school and after-school physical activity classes). These policies would be available for all residents, both affluent- and less affluent. Therefore, policies of local authorities provide one possible explanation for the low prevalence of adolescent overweight/obesity, as observed in this study among Jewish towns characterized by high inequalities. Another possible explanation lies at the individual level, suggesting that in towns with higher inequalities the more affluent residents may advocate towards more investments of local authorities in promoting healthier environment. Therefore, less affluent adolescents living in these towns can gain from physical and social environments that promote health. From a more social perspective, it may be hypothesized that towns with affluent sub-communities may form social norms that enhance healthy lifestyles, including physical activity and healthy nutrition. Again, less affluent adolescents in these towns may benefit from these health promoting social norms. These assumptions should be explored in future research focusing on both macro- and micro-level indicators of wealth and inequality. Two spatial factors were examined in this study: intra-regional and country-scale pripherality/centrality. Most previous studies on spatial correlates of overweight/obesity usually focused on urbanity-rurality ${ }^{[18,19]}$. Thus, for the sake of discussion, 'urbanity-rurality' can be seen as corresponding to 'center-periphery', assuming that the more central settings are more likely to be urban, while peripheral setting are more likely to be rural.

Similarly to the socioeconomic factors, peripherality level was also found to be related to adolescent overweight/ obesity in opposite directions among Jewish and Arab towns (positive and negative correlations, respectively). The higher prevalence of adolescent overweight/obesity in peripheral Jewish towns and in central Arab towns stands in line with previous studies conducted in developed countrie ${ }^{[19-21]}$ and in developing countries $^{[14,18,22}$, respectively. These findings may be attributed to the socioeconomic gap between central and peripheral towns that was observed in this study. The relatively high SER observed in central towns (compared to peripheral towns) may hold an inverse impact of adolescent overweight/obesity in Jewish and Arab towns. In the Jewish sector, local authorities of central towns may have more recourses to invest in creating healthy environments (e.g. high access to healthy foods and recreational settings), which, in turn, potentially facilitates non-obesogenic behaviors (e.g. physical activity, healthy eating). On the other hand, in the Arab sector high SER of central Arab towns may be associated with increased exposure to more modern environments and lifestyles, which are likely to be obesogenic (e.g. high access to fast-food restaurants, increased car-dependence). At the same time, peripheral Arab towns are more likely to be associated with more traditional lifestyles, which tend to be healthier (e.g. daily walking and Mediterranean diet).

The socioeconomic gap between the center and periphery in Israe ${ }^{[42]}$ was illustrated in this study, as peripheral towns were found more likely to be poorer. Thus, it is reasonable to assume that the observed association between peripherality and obesity may be attributed to various socioeconomic factors. However, this does not seem to be the case in Arab towns, as after adjusting for town-level SER, the towns' centrality remained significantly correlated adolescent overweight/obesity. These findings are opposed to previous studies, in which the urban-rural gap in overweight/obesity was attuned or insignificant after adjustment for socioeconomic factors ${ }^{[19,43,44]}$. The low rate of adolescent overweight/obesity in Arab peripheral towns that was observed in this study may be attributed to the low exposure to modern environments/lifestyles in those towns, which is enhanced by their geographical isolation and segregation that maintains a "closed" society with little cultural exchange with neighboring communities ${ }^{[36,37]}$. Therefore, our findings highlight the importance of the spatial dimension in the obesity epidemic in the Arab sector in Israel, and future research is needed to further deepen our understanding of the impact of peripherality/ centrality on overweight/obesity in Israel, and particularly in the Arab population.

To the best of our knowledge, this study is the first to distinguish between different scales of peripheriality (country vs. intra-regional). This distinction is especially important given the different patterns of correlations between socioeconomic and spatial characteristics that were observed in Jewish and Arab towns.

In our study, Jewish towns were found more likely to be richer if they were in a central location at both regional and country scale (i.e. closer to Tel-Aviv district). However, in the Arab sector, a towns ' wealth was found to be related only with its centrality within its region. In other words, in the Jewish sector, geographical peripherality (at both country and regional levels) 
was found to correspond with economic peripherality, while in the Arab sector this is the case only for intra-regional peripherality. This implies that vicinity to Israel's economical and business center (Tel-Aviv area) is related to higher SER in Jewish towns, but not in Arab towns, whose SER is mainly affected by their intra-regional centrality. These finding well reflect other social, cultural and economic dimensions of the Israeli Arab population as an ethnic minority that suffers from social segregation and socioeconomic deprivation ${ }^{[30,31,45]}$. This may explain why in the Arab sector intra-regional centrality explained more of the variance in overweight/obesity than did country-scale peripherality.

A major strength of this study lies in its unique setting including two distinctive communities within one country, one of which is more affluent and modern, while the other is more deprived and traditional. And indeed, our findings in Jewish and Arab towns correspond with previous studies that were conducted in developed/modern and developing/traditional countries, respectively, and thereby emphasize the potential impact of town-level factors on overweight/obesity. In addition, this study used objective measures of weight and height, unlike previous studies that used self-reported measures of BMI, which may be biased.

Some limitations of this study should be noted. First, by its nature the study's cross-sectional ecological design does not allow to identify causal relationships at the individual level. Secondly, the sample used here was not randomly selected, and thus may limit the results generalizability. However, the results do have general implications, given the large overall sample size $(n=114,422)$ and the large samples within each town $(n \geq 100)$. Third, the association between wealth and overweight/obesity may depend on the wealth variable studied ${ }^{[14]}$. The SER measures used in this study integrate various measures/characteristics and thus, it is hard to decipher the impact of each measure and their inter-relations within the general SER measure. Finally, the number of Arab towns included in this study is relatively small (compared to the number of Jewish towns), yet this stands in line with the proportion of the Arab population in Israel: Arab towns comprised $17 \%$ of the towns in the study sample, while Arab towns consist of $11 \%$ of the towns in Israel (135 out of $1,205)$ and the Arab population consists of $20 \%$ of the total population in Israel $(1,683.2 \mathrm{~K} \text { out of } 8,134.5 \mathrm{~K})^{[46]}$.

\section{Conclusion}

To conclude, this study explored socioeconomic and spatial variations in adolescent overweight/obesity in Israel, while distinguishing between Jewish and Arab towns. Our findings highlight the importance of macro level factors enhancing obesity, and may suggest that national policy should focus on town-level interventions to combat the obesity epidemic among adolescents. Several explanations to the study's findings were suggested, involving social, environmental and individual factors. However, given the ecological nature of our analysis, future research, preferably of multi-level design, is needed to establish substantial evidence.

Funding: Analysis and writing time was supported through a grant from the Israel Science Foundation (ISF 916/12).

\section{References}

1. Must, A., Strauss, R.S. Risks and consequences of childhood and adolescent obesity. (1999) Int J Obes Relat Metab Disord Suppl 2: S2-11.

2. Singh, A.S., Mulder, C., Twisk, J.W., et al. Tracking of childhood overweight into adulthood: a systematic review of the literature. (2008) Obesity Reviews 9(5): 474-488.

3. Lobstein, T., Baur, L., \& Uauy, R. Obesity in children and young people: a crisis in public health. (2004) Obesity Reviews 5(s1): 4-104.

4. Kosti, R.I., Panagiotakos, D.B. The epidemic of obesity in children and adolescents in the world. (2006) Cent Eur J Public Health 14(4): 151-159.

5. Gupta, N., Goel, K., Shah, P., et al. Childhood obesity in developing countries: epidemiology, determinants, and prevention. (2012) Endocr Rev 33(1): 48-70.

6. Manyanga, T., El-Sayed, H., Doku, D.T., et al. The prevalence of underweight, overweight, obesity and associated risk factors among school-going adolescents in seven African countries. (2014) BMC Public Health 14(1): 887.

7. Olds, T., Maher, C., Zumin, S., et al. Evidence that the prevalence of childhood overweight is plateauing: data from nine countries. (2011) Int J Pediatr Obes 6(5-6): 342-360.

8. Stamatakis, E., Wardle, J., Cole, T.J. Childhood obesity and overweight prevalence trends in England: evidence for growing socioeconomic disparities. (2010) Int J Obes (Lond) 34(1): 4147.

9. Dunton, G.F., Kaplan, J., Wolch, J., et al. Physical environmental correlates of childhood obesity: a systematic review. (2009) Obes Rev 10(4): 393-402.

10. Sallis, J.F., Glnaz, K. The role of built environment in physical activity, eating, and obesity in childhood. (2006) Future Child 16(1): 89-108.

11. McLaren, L. Socioeconomic status and obesity. (2007) Epidemiol Rev 29: 29-48.

12. Wang, Y. Cross-national comparison of childhood obesity: the epidemic and the relationship between obesity and socioeconomic status. (2001) Int J Epidemiol 30(5): 1129-1136.

13. Shrewsbury, V., Wardle, J. Socioeconomic Status and Adiposity in Childhood: A Systematic Review of Cross-sectional Studies 1990-2005. (2008) Obesity (Silver Spring) 16(2): 275284.

14. Martorell, R., Kettel Khan, L., Hughes, M.L., et al. Overweight and obesity in preschool children from developing countries. (2000) Int J Obes Relat Metab Disord 24(8): 959-967.

15. Wilkinson, R.G. The impact of inequality. (2005) New York: New Press.

16. Pickett, K.E., Kelly, S., Brunner, E., et al. Wider income gaps, wider waistbands? An ecological study of obesity and income inequality. (2005) J Epidemiol Community Health 59(8): 670-674.

17. Due, P., Damsgaard, M.T., Rasmussen, M., et al. Socioeconomic position, macroeconomic environment and overweight among adolescents in 35 countries. (2009) Int J Obes(Lond) 33(10): 1084-1093.

18. Mohan, B., Kumar, N., Aslam, N., et al. Prevalence of sustained hypertension and obesity in urban and rural school going children in Ludhiana. (2003) Indian Heart J 56(4): 310-314.

19. Sjöberg, A., Moraeus, L., Yngve, A., et al. Overweight and 
obesity in a representative sample of schoolchildren-exploring the urban-rural gradient in Sweden. (2011) Obesity Reviews 12(5): 305-314.

20. Bertoncello, C., Cazzaro, R., Ferraresso, A., et al. Prevalence of overweight and obesity among school-aged children in urban, rural and mountain areas of the Veneto Region, Italy. (2008) Public Health Nutr 11(9): 887-890.

21. Liu, J., Bennett, K.J., Harun, N., et al. Urban-Rural Differences in Overweight Status and Physical Inactivity among US Children Aged 10-17 Years. (2008) J Rural Health 24(4): 407415.

22. Andegiorgish, A.K., Wang, J., Zhang, X., et al. Prevalence of overweight, obesity, and associated risk factors among school children and adolescents in Tianjin, China. (2012) Eur J Pediatr 171(4): 697-703.

23. Gross, R., Brammli-Greenberg, S., Gordon, B., et al. Population-based trends in male adolescent obesity in Israel 19672003. (2009) J Adolesc Health 44(2): 195-198.

24. Sheffer, R., Calderon-Margalit, R. Trends in overweight, obesity and blood pressure among Israeli working adults-implications for public health. (2008) Eur J Public Health 18(2): 121-125.

25. Kaluski, D.N., Keinan-Boker, L., Stern, F., et al. BMI may overestimate the prevalence of obesity among women of lower socioeconomic status. (2007) Obesity (Silver Spring) 15(7): 1808-1815.

26. Jabareen, Y. Employment among Arabs in Israel: the challenge of the Israeli economy. (2010) Forum Keisaria, The Israeli Democratic Institute.

27. Israeli Central Bureau of Statistics (ICBS). Characterization and Classification of Local Authorities by the Socio-Economic Level of the Population -2006. Jerusalem (2008).

28. National Insurance Institute of Israel. Average Wage and Income by Locality and by Various Economic Variables 2009. Jerusalem (2011).

29. ICBS. Peripherality Index of Local Authorities 2004 - New Development. Jerusalem (2008a). Israel: Central Bureau of Statistics.

30. The Van-Leer Jerusalem Institute. Arab Society in Israel: Population, Society, Economy. The Van-Leer Jerusalem Institute, Israel. (Hebrew) (2013).

31. Yashiv, E., Kasir, N. The Labor Market of Israeli Arabs: Key Features and Policy Solutions. (2014) Tel-Aviv University Israel.

32. Sallis, J.F., Glanz, K. Physical activity and food environments: solutions to the obesity epidemic. (2009) Milbank Quarterly $87(1)$ : 123-154
33. Glanz, K., Sallis, J.F., Saelens, B.E., et al. Healthy nutrition environments: concepts and measures. (2005) Am J Health Promot 19(5): 330-333.

34. Wang, Y., Beydoun, M. A. The obesity epidemic in the United States-gender, age, socioeconomic, racial/ethnic, and geographic characteristics: a systematic review and meta-regression analysis. (2007) Epidemiol Rev 29(1): 6-28.

35. Wickrama, K. T., Wickrama, K. A., Bryant, C. M. Community influence on adolescent obesity: Race/ethnic differences. (2006) J Youth Adolesc 35(4): 641-651.

36. Ford, E.S., Merritt, R.K., Heath, G.W., et al. Physical activity behaviors in lower and higher socioeconomic status populations. (1991) Am J Epidemiol 133(12): 1246-1256.

37. Pomerleau, J., McKee, M., Robertson, A., et al. Physical inactivity in the Baltic countries. (2000) Preventive medicine 31(6): 665-672.

38. Wardle, J., Steptoe, A. Socioeconomic differences in attitudes and beliefs about healthy lifestyles. (2003) J Epidemiol Community Health 57(6): 440-443.

39. Giskes, K., van-Lenthe, F.J., Turrell, G., et al. Socioeconomic position at different stages of the life course and its influence on body weight and weight gain in adulthood: a longitudinal study with 13-year follow-up. (2008) Obesity (Silver Spring) 16(6): 1377-1381.

40. Ezzati, M., Vander-Hoorn, S., Lawes, C.M., et al. Rethinking the "diseases of affluence" paradigm: global patterns of nutritional risks in relation to economic development. (2005) PLoS Med 2(5): e133.

41. Bjornstrom, E.E. An examination of the relationship between neighborhood income inequality, social resources, and obesity in Los Angeles county. (2011) Am J Health Promot 26(2): 109115.

42. ICBS. Society in Israel - report number 3: Gaps between the center and periphery. (2010) (Hebrew).

43. Neuman, M., Kawachi, I., Gortmaker, S., et al. Urban-rural differences in BMI in low-and middle-income countries: the role of socioeconomic status. (2013) The Am J Clin Nutr 97(2): 428436.

44. Sayeed, M.A., Ali, L., Hussain, M.Z., et al. Effect of socioeconomic risk factors on the difference in prevalence of diabetes between rural and urban populations in Bangladesh. (1997) Diabetes Care 20(4): 551-555.

45. ICBS. The Arab Population 2008. Jerusalem (2010a) Israel: Central Bureau of Statistics.

46. ICBS. Statistical abstract of Israel 2014: Localities (1) and population, by population group, district, and natural region. (2014). 